\title{
Simultaneous Bilateral Hypertensive Putaminal or Thalamic Hemorrhage: Case Report and Systematic Review of the Literature
}

\author{
Eşzamanl Bilateral Hipertansif Putaminal veya Talamik Kanama: \\ Olgu Sunumu ve Literatürün Sistematik Gözden Geçirilmesi
}

Kenichi KONO, Tomoaki TERADA

Wakayama Rosai Hospital, Department of Neurosurgery, Wakayama, Japan

Corresponding Author: Kenichi KONO / E-mail: vyr01450@gmail.com

\begin{abstract}
Simultaneous multiple hypertensive intracranial hemorrhage is rare, and its mechanism is unclear. We report a case of simultaneous hypertensive bilateral thalamic hemorrhage. A 58-year-old man presented with sudden mild right hemiparesis. Computed tomography 1 hour after the onset showed bilateral thalamic hemorrhage. Gradient-echo T2*-weighted magnetic resonance imaging showed 17 microbleeds. The patient was treated with medication, discharged home, and achieved a modified Rankin scale of 1 at 3 months from the onset. Additionally, by systematically searching in PubMed, we found 41 cases of simultaneous bilateral hypertensive putaminal or thalamic hemorrhage, including our case: 18 bilateral putaminal, 12 bilateral thalamic, and 11 unilateral putaminal and contralateral thalamic hemorrhage. Symmetric hemorrhage occurred more frequently than expected ratios of hemorrhage occurring randomly in terms of location ( $p=0.013$; Fisher's exact test). These new findings raise the hypothesis that patients may have symmetrically vulnerable vessels. Such conditions would result in coincidence or subsequent rupture of perforating arteries or micro-aneurysms by increased blood pressure and cause symmetric hemorrhages. Studies on the distribution of microbleeds may address these issues.
\end{abstract}

KEYWORDS: Simultaneous multiple intracranial hemorrhages, Hypertension, Microbleeds, Putaminal hemorrhage, Thalamic hemorrhage

öz

Eş zamanlı çoklu hipertansif intrakraniyal kanama nadirdir ve mekanizması açık değildir. Bir eş zamanlı hipertansif bilateral talamik kanama olgusu bildiriyoruz. 58 yaşında bir erkek ani hafif sağ hemiparezi ile geldi. Başlangıçtan 1 saat sonra bilgisayarlı tomografi bilateral talamik kanama gösterdi. Gradiyent eko T2*-ağırlıklı manyetik rezonans görüntüleme 17 mikrokanama gösterdi. Hasta ilaçla tedavi edildi, eve gönderildi ve başlangıçtan 3 ay sonra modifiye Rankin ölçeği değeri 1 bulundu. Ek olarak PubMed'de sistematik bir arama yaptığımızda kendi olgumuz dahil 41 eş zamanlı bilateral hipertansif putaminal veya talamik kanama olgusu bulduk: 18 bilateral putaminal, 12 bilateral talamik ve 11 unilateral putaminal ve kontralateral talamik kanama. Simetrik kanama, konum açısından rastgele beklenecek, beklenen kanama oranlarından daha sık bulundu ( $p=0,013$; Fisher kesin testi). Bu yeni bulgular hastalarda simetrik narin damarlar bulunabileceği hipotezini düşündürmektedir. Bu gibi durumlar artmış kan basıncı nedeniyle perforan arterler veya mikroanevrizmaların aynı anda veya arka arkaya rüptürüne yol açıp simetrik kanamalara neden olacaktır. Mikrokanamaların dağılımı konusunda çalışmalar bu konuları açıklığa kavuşturabilir.

ANAHTAR SÖZCÜKLER: Eş zamanlı çoklu intrakraniyal kanamalar, Hipertansiyon, Mikrokanamalar, Putaminal kanama, Talamik kanama

\section{INTRODUCTION}

Hypertensive intracranial hemorrhage $(\mathrm{ICH})$ is generally solitary. Simultaneous multiple ICHs are rare and associated with hypertension, amyloid angiopathy, hemorrhagic infarction, coagulation defects, and sinus thrombosis $(4,11)$. The incidence of multiple hypertensive $\mathrm{ICH}$ is reported as $0.9 \%$ to $4.7 \%(1,11,18,20,24,28)$, and its mechanism is unclear. We report a case of simultaneous hypertensive bilateral thalamic hemorrhage, and review the literature and analyze data regarding the location of hemorrhage.

\section{CASE PRESENTATION}

A 58-year-old man presented with sudden mild right hemiparesis. Computed tomography 1 hour after the onset showed bilateral thalamic hemorrhage (Figure 1A). Gradient-echo $2^{*}$-weighted magnetic resonance imaging (MRI) showed 17 microbleeds (Figure 1B). There were three microbleeds on each side of the putamen and two microbleeds on each side of the thalamus. MRI and magnetic resonance angiography showed no vessel abnormalities and no other lesions, such as tumors. As the patient had a history of hypertension and had stopped anti-hypertensive drugs by his own decision, ICH was considered to be associated with hypertension. The patient was treated with medication and discharged home, and achieved a modified Rankin scale of 1 at 3 months from the onset. 

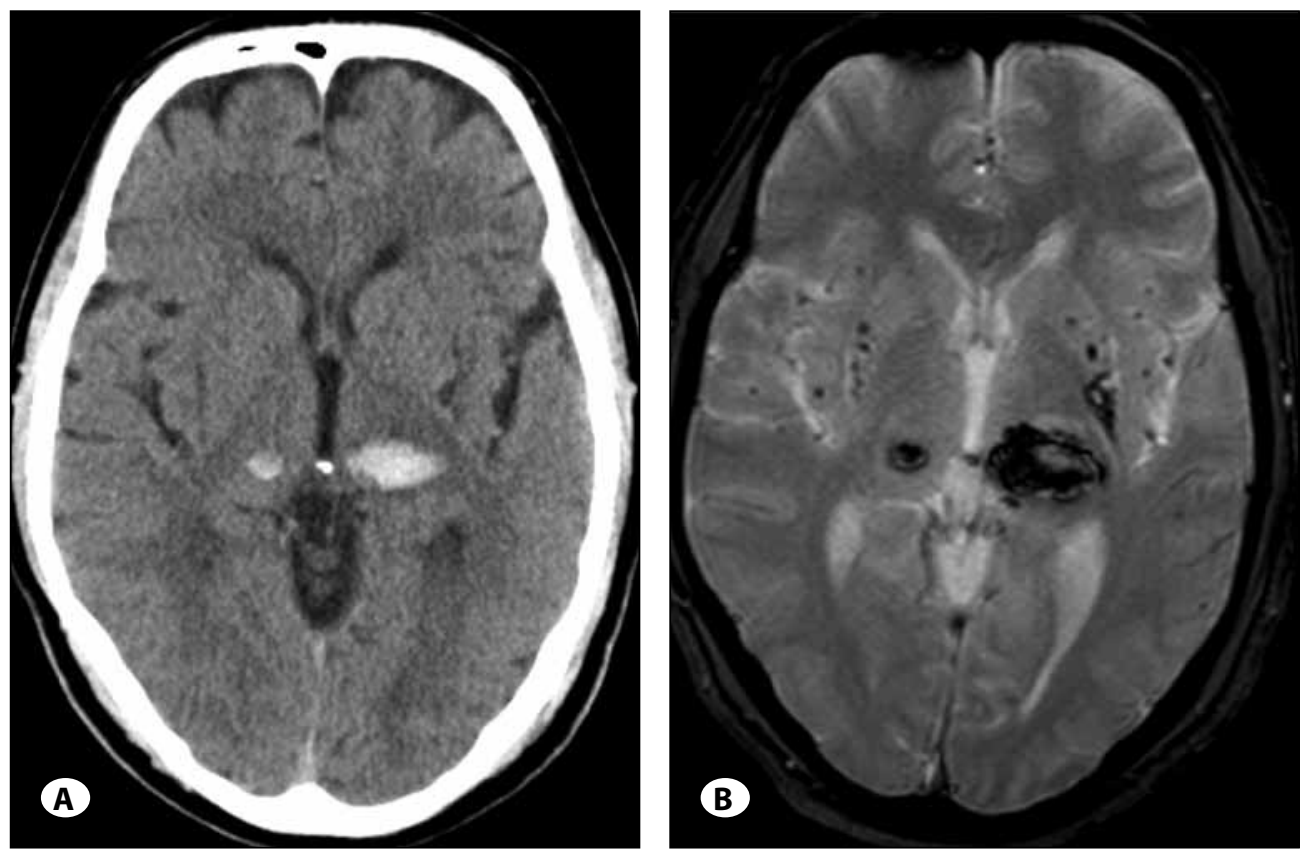

Figure 1: A) Computed tomography shows bilateral thalamic hemorrhage. B) Gradient-echo T2*weighted magnetic resonance imaging shows the hemorrhage and multiple microbleeds.

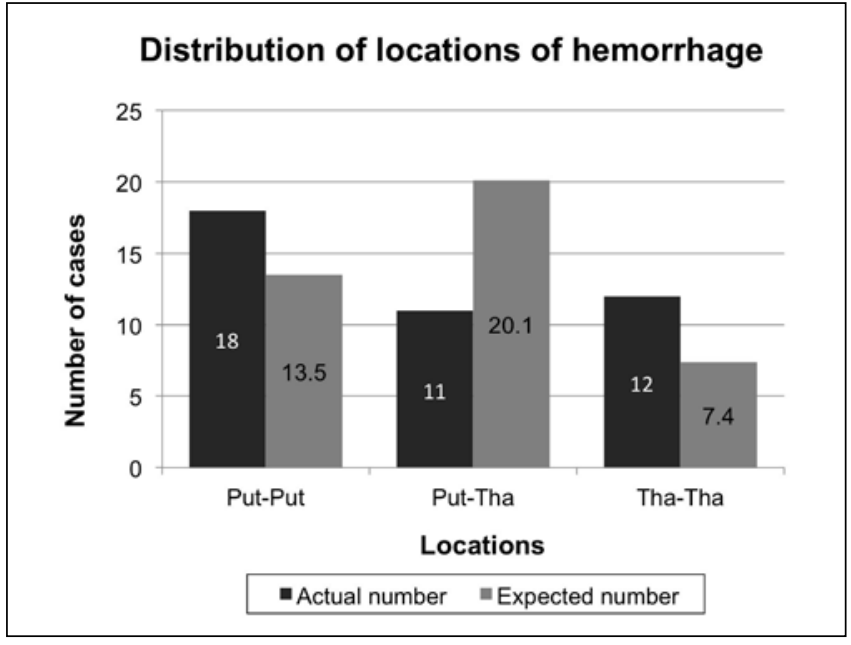

Figure 2: Distribution of locations of hemorrhage are shown. Forty-one cases of simultaneous bilateral hypertensive putaminal or thalamic hemorrhage were classified into three categories: bilateral putaminal (Put-Put), unilateral putaminal and contralateral thalamic (Put-Tha), and bilateral thalamic hemorrhage (Tha-Tha). Actual and expected numbers of cases are shown in the graph. The expected numbers were calculated based on the assumption that hemorrhage occurs at random in locations regardless of other hemorrhagic locations. Bilateral symmetric hemorrhage (Put-Put and Tha-Tha) occurred more frequently in the actual cases than in the expected cases. Put $=$ putamen; Tha $=$ thalamus.

\section{Review of the Literature and Statistical Analysis}

We systematically searched the literature by PubMed using several keywords, including "simultaneous", "multiple", "bilateral", "hypertensive", "hemorrhage/hematoma", "intracranial/ intracerebral", "thalamic/thalamus", and "putaminal/putamen". We narrowed down articles by conditions that "simultaneous" and "hemorrhage/hematoma" appear in the titles. After checking titles and abstracts, 23 articles on simultaneous multiple hypertensive ICHs were found. There were 105 cases of simultaneous multiple ICHs in the 23 articles and our case report (1, 3, 5, 7-9, 11-15, 17-20, 22-29). In references in the literature $(5,26)$, we found nine additional cases of simultaneous hypertensive $\mathrm{ICH}$, which were all written in Japanese and not cited by PubMed. We did not include these nine cases because this could cause difficulty for other researchers to trace our search and examine the statistical analysis. Among the 105 cases, there were 10 non-hypertensive ICH and nine hypertensive $\mathrm{ICH}$ without a description of the hemorrhagic sites. Therefore, there remained 86 cases of simultaneous multiple hypertensive ICHs with a description of the location of hemorrhage. The locations of hemorrhage were the putamen $(n=73)$, thalamus $(n=49)$, subcortex $(n=18)$, cerebellum $(n=16)$, pons $(n=14)$, and caudate nucleus $(n=2)$. We selected cases of bilateral putaminal or thalamic hemorrhage because the putamen and thalamus are the two most frequent locations of hypertensive ICH (29). One case of unilateral thalamic and putaminal hemorrhage was excluded from this study. Finally, we analyzed 41 cases of simultaneous bilateral hypertensive putaminal or thalamic hemorrhage, including our case. The mean age \pm standard deviation was $60.6 \pm 12.0$ years (range, 35-89 years). There were 24 males and 17 females. There were 18 bilateral putaminal, 12 bilateral thalamic, and 11 unilateral putaminal and contralateral thalamic hemorrhage cases. There were 47 hemorrhagic sites in the putamen $(57 \% ; a=0.57)$ and 35 in the thalamus $(43 \% ; b=0.43)$. If hemorrhage randomly occurred in terms of location, regardless of the location of other hemorrhages, the expected ratios of hemorrhagic locations were 33\% $\left(a^{2}\right), 18 \%\left(b^{2}\right)$, and 49\% (2ab) 
at the bilateral putamen, bilateral thalamus, and unilateral putamen and contralateral thalamus, respectively. We performed statistical analysis using SPSS version 20 (IBM Corp., Armonk, NY, USA). p<0.05 was considered as significant. Symmetric hemorrhage occurred significantly more frequently in 41 cases compared with the expected ratios ( $p=0.013$; Fisher's exact test). Namely, bilateral putaminal or bilateral thalamic hemorrhage occurred more frequently than unilateral putaminal and contralateral thalamic hemorrhage based on the expected numbers when each hemorrhage occurs at random in terms of location, regardless of the location of other hemorrhages (Figure 2).

\section{DISCUSSION}

The majority of spontaneous $\mathrm{ICHs}$ are associated with hypertension $(3,28)$. Hypertensive ICH commonly occurs at the putamen, thalamus, pons, and cerebellum. The putamen and thalamus are the most common sites of hypertensive ICH (29). Our review of 86 cases of simultaneous multiple hypertensive ICHs shows a similar trend on the distribution of location. Lenticulostriate arteries are responsible for putaminal hemorrhage and originate from the middle cerebral artery (M1) or proximal anterior cerebral artery (A1) in the anterior circulation. Thalamoperforating arteries are responsible for thalamic hemorrhage and originate from the posterior cerebral arteries in the posterior circulation. Chronic hypertension produces hyaline degeneration of perforating arteries. Rupture of micro-aneurysms or perforating arteries is considered a cause of hypertensive $\mathrm{ICH}$. Although the mechanism of bilateral simultaneous hypertensive $\mathrm{ICH}$ is unclear, two possible mechanisms have been proposed (3, $11,13,18,24)$. First, coincidental rupture of bilateral microaneurysms or perforating arteries can cause bilateral ICHs. Second, subsequent rupture of bilateral micro-aneurysms or perforating arteries can cause multiple ICHs. An initial hemorrhage increases blood pressure, which may result in subsequent contralateral hemorrhage. Both mechanisms are probable. Which mechanism causes bilateral ICH in each case is difficult to determine unless subsequent neurological symptoms of each side are observed. Although not proven, rupture of bilateral micro-aneurysms or perforating arteries occurring at exactly the same time may be rare. Therefore, we consider that subsequent rupture is more probable than coincidental rupture. The time lag of subsequent rupture can be from a few seconds to a few hours. The initial rupture increases systemic blood pressure, which may result in rupture of most vulnerable vessels at other sites.

Our analysis showed that symmetrical bilateral hemorrhage occurs more frequently than asymmetric bilateral hemorrhage. This finding raises the hypothesis that perforation of arteries or micro-aneurysms are prone to occurring at symmetrical locations. Namely, the distribution of hyaline degeneration of lenticulostriate or thalamoperforating arteries is likely to be symmetric. Symmetrical distribution of vulnerable vessels could explain the deviation to a high frequency of occurrence of symmetrical bilateral hemorrhage. Microbleeds are associated with $\mathrm{ICH}(2)$, and there is a close positional association between recurrent $\mathrm{ICH}$ and prior microbleeds (21). Sorimachi et al. reported that the number of microbleeds is significantly higher in simultaneous multiple ICHs (mode; 15-19) than in single $\mathrm{ICH}$ (mode; 1-4) (20). The number of microbleeds in our case $(n=17)$ is consistent with their results. In their study, the distribution of location of microbleeds was not examined. Although studies have examined the distribution of location of microbleeds $(10,16)$, there are no studies on laterality of distribution of microbleeds. Jia et al. demonstrated that systolic blood pressure had a significant association with microbleeds in the territory of the posterior cerebral artery (6). Their study may be supportive evidence of our hypothesis that microbleeds tend to be distributed symmetrically because perforating arteries originating from the anterior or posterior circulation are responsible for putaminal or thalamic hemorrhage, respectively. Trends of distribution of microbleeds were unable to be determined from our single case. A large-scale study focusing on laterality of distribution of microbleeds by $\mathrm{T} 2{ }^{*}$-weighted MRI may address our hypothesis that distribution of hyaline degeneration of lenticulostriate or thalamoperforating arteries is prone to be symmetric.

In our systematic review, there may be selection bias because some of the literature included case reports without complete surveys. Symmetric bilateral ICH is likely to be reported rather than asymmetric bilateral ICH. When only complete surveys of consecutive ICHs were selected, there were 27 cases of simultaneous bilateral hypertensive putaminal or thalamic hemorrhage among 5334 cases of $\mathrm{ICH}$ in total $(9,20,24$, $26,29)$. The same statistical analysis of hemorrhagic sites as described above showed $p=0.050$ (details not shown), and there was still a strong trend of deviation to symmetrical hemorrhage. Therefore, we consider that our analysis and discussion are still valid.

\section{CONCLUSION}

We report a rare case of simultaneous hypertensive bilateral $\mathrm{ICH}$. A systematic review found 41 cases of simultaneous hypertensive putaminal or thalamic hemorrhage. In these cases, symmetrical hemorrhage frequently occurs. These new findings suggest that patients may have symmetrically vulnerable vessels. Further examinations of the distribution of vulnerable vessels by $T 2^{*}$-weighted MRI may address these issues.

\section{REFERENCES}

1. Balasubramaniam S, Nadkarni TD, Goel A: Simultaneous thalamic and cerebellar hypertensive haemorrhages. Neurol India 55:183-184, 2007

2. Bokura H, Saika R, Yamaguchi T, Nagai A, Oguro H, Kobayashi $S$, Yamaguchi S: Microbleeds are associated with subsequent hemorrhagic and ischemic stroke in healthy elderly individuals. Stroke 42:1867-1871, 2011 
3. Hickey WF, King RB, Wang AM, Samuels MA: Multiple simultaneous intracerebral hematomas. Clinical, radiologic, and pathologic findings in two patients. Arch Neurol 40: 519-522, 1983

4. Ikram MA, Wieberdink RG, Koudstaal PJ: International epidemiology of intracerebral hemorrhage. Curr Atheroscler Rep 14:300-306, 2012

5. Imai K: Bilateral simultaneous thalamic hemorrhages--case report. Neurol Med Chir (Tokyo) 40:369-371, 2000

6. Jia Z, Mohammed W, Qiu Y, Hong X, Shi H: Hypertension increases the risk of cerebral microbleed in the territory of posterior cerebral artery: A Study of the Association of Microbleeds Categorized on a Basis of Vascular Territories and Cardiovascular Risk Factors. J Stroke Cerebrovasc Dis 23(1):e5-11, 2014

7. Kabuto M, Kubota T, Kobayashi H, Nakagawa T, Arai Y, Kitai R: Simultaneous bilateral hypertensive intracerebral hemorrhages--two case reports. Neurol Med Chir (Tokyo) 35:584-586, 1995

8. Kohshi K, Abe H, Tsuru E: Simultaneous hypertensive intracerebral hematomas: Two case reports. J Neurol Sci 181:137-139, 2000

9. Lin $\mathrm{CN}$, Howng $\mathrm{SL}$, Kwan AL: Bilateral simultaneous hypertensive intracerebral hemorrhages. Gaoxiong Yi Xue Ke Xue Za Zhi 9:266-275, 1993

10. Liu PF, Cui YZ, Na J, Gao PY: Cerebral microbleeds - prevalence, distribution and risk factors in northeast population without preceding large-area stroke. Chin Med J (Engl) 123:286-290, 2010

11. Mauriño J, Saposnik G, Lepera S, Rey RC, Sica RE: Multiple simultaneous intracerebral hemorrhages: Clinical features and outcome. Arch Neurol 58:629-632, 2001

12. Miyasaka Y, Nakayama K, Matsumori K, Beppu T, Kurata A, Satoh K, Kitahara T, Morii S, Owada T, Yada K: Bilateral hypertensive intracerebral hemorrhage diagnosed by $\mathrm{CT}$ scan: report of five cases and review of literature. Neurol Med Chir (Tokyo) 22:661-667, 1982

13. Nakamura T, Kadoya S, Umemori T, Suzuki T, Kwaku R: A case report of simultaneous multiple intracerebral hematomas. No Shinkei Geka 16:435-439, 1988

14. Ozdemir O, Calisaneller T, Yildirim E, Altinors N: Simultaneous supra and infratentorial hypertensive intracerebral haemorrhage. J Clin Neurosci 14:775-777, 2007

15. Raabe A, Krug U: Migraine associated bilateral intracerebral haemorrhages. Clin Neurol Neurosurg 101:193-195, 1999

16. Roob G, Lechner A, Schmidt R, Flooh E, Hartung HP, Fazekas F: Frequency and location of microbleeds in patients with primary intracerebral hemorrhage. Stroke 31:2665-2669, 2000
17. Sato M, Tanaka S, Kohama A, Sone T, Fukunaga M, Morita R: Spontaneous bilateral intracerebral hemorrhage occurring simultaneously--case report. Neurol Med Chir (Tokyo) 26: 545-547, 1986

18. Shiomi N, Miyagi T, Koga S, Karukaya T, Tokutomi T, Shigemori M: Simultaneous multiple hypertensive intracerebral hematoma. No Shinkei Geka 32:237-244, 2004

19. Silliman S, McGill J, Booth R: Simultaneous bilateral hypertensive putaminal hemorrhages. J Stroke Cerebrovasc Dis 12: 44-46, 2003

20. Sorimachi T, Ito Y, Morita K, Fujii Y: Microbleeds on gradientecho T2 $\left(^{*}\right)$-weighted MR images from patients with multiple simultaneous intracerebral haemorrhages. Acta Neurochir (Wien) 149:171-176, 2007

21. Sueda $Y$, Naka H, Ohtsuki T, Kono T, Aoki S, Ohshita T, Nomura E, Wakabayashi S, Kohriyama T, Matsumoto M: Positional relationship between recurrent intracerebral hemorrhage/ lacunar infarction and previously detected microbleeds. AJNR Am J Neuroradiol 31:1498-1503, 2010

22. Sugiura M, Himuro H, Tanikawa T, Beppu T: A case of bilateral hypertensive intracerebral hemorrhage which occurred simultaneously (author's transl). No Shinkei Geka 10:193-198, 1982

23. Sunada I, Nakabayashi H, Matsusaka Y, Nishimura K, Yamamoto S: Simultaneous bilateral thalamic hemorrhage: Case report. Radiat Med 17:359-361, 1999

24. Takeuchi S, Takasato Y, Masaoka H, Hayakawa T, Yatsushige $\mathrm{H}$, Sugawara T: Simultaneous multiple hypertensive intracranial hemorrhages. J Clin Neurosci 18:1215-1218, 2011

25. Tanikake T, Kawaguchi S, Tada T, Kyoi K, Utsumi S, Nakasone K: Simultaneous, bilateral hypertensive intracranial hematomas. No Shinkei Geka 11:1085-1090, 1983

26. Tanno H, Ono J, Suda S, Karasudani H, Yamakami I, Isobe K, Watanabe Y: Simultaneous, multiple hypertensive intracerebral hematomas: report of 5 cases and review of literature. No Shinkei Geka 17:223-228, 1989

27. Uno $M$, Hondo $H$, Matsumoto K: Simultaneous supra- and infratentorial hypertensive intracerebral hemorrhage. No Shinkei Geka 19:933-938, 1991

28. Weisberg L: Multiple spontaneous intracerebral hematomas: Clinical and computed tomographic correlations. Neurology 31:897-900, 1981

29. Yen $C P$, Lin $C L$, Kwan AL, Lieu AS, Hwang SL, Lin CN, Howng SL: Simultaneous multiple hypertensive intracerebral haemorrhages. Acta Neurochir (Wien) 147:393-399, 2005 